\title{
Silencing of ATPase family AAA domain-containing protein 2 inhibits migration and invasion of colorectal cancer cells
}

\author{
S. $\mathrm{HONG}^{1}$, M. $\mathrm{BI}^{2}$, Z. YAN ${ }^{3}$, D. SUN ${ }^{4}$, L. $\mathrm{LING}^{4}$, C. ZHAO ${ }^{1, *}$ \\ ${ }^{1}$ Department of Physiology, College of Basic Medical Sciences, Jilin University, Changchun, Jilin 130021, People's Republic of China; ${ }^{2}$ Department \\ of Ophthalmology, China-Japan Union Hospital of Jilin University, Changchun, Jilin 130033, People's Republic of China; ${ }^{3}$ Endoscopy Center, \\ China-Japan Union Hospital of Jilin University, Changchun, Jilin 130033, People's Republic of China; ${ }^{4}$ Department of Colorectal and Anal Surgery, \\ The First Hospital of Jilin University, Changchun, Jilin 130021, People's Republic of China
}

*Correspondence: chunyan_zh2012@sina.com

Received December 22, 2015 / Accepted May 16, 2016

\begin{abstract}
Colorectal cancer is one of the most common malignant tumors with a high rate of distant metastasis, postoperative recurrence and mortality. ATPase family AAA domain-containing protein 2 (ATAD2), a member of ATPase family, is highly expressed in various cancers, including colorectal cancer. However, whether ATAD2 plays a role in the migration and invasion of colorectal cancer cells remains unknown. In this study, we established ATAD2 knockdown in colorectal cancer cell lines by RNA interference and found that silencing of ATAD2 inhibited the migration and invasion ability of Caco-2 and SW-480 cells. Moreover, ATAD2 silencing suppressed epithelial-mesenchymal transition (EMT), and reduced the expression and enzymatic activity of matrix metalloproteinases (MMPs) in Caco-2 and SW-480 cells. In summary, our results suggest that silencing of ATAD2 inhibits migration and invasion of colorectal cancer cells by suppressing EMT and decreasing the activity of MMPs. Hence, ATAD2 could be considered as a novel molecular marker of metastatic colorectal cancer, and it may provide new insights for clinical diagnosis and treatment of colorectal cancer.
\end{abstract}

Key words: colorectal cancer, ATAD2, migration, invasion, EMT, MMPs

Colorectal cancer is the third most common malignant tumor in the world, with annually 1.2 million new cases and over 0.6 million deaths [1]. The etiology of colorectal cancer includes dietary habit, chronic colorectal inflammation, genetic factors, parasite infection and environmental factors [2]. At present, the main treatment strategy for colorectal cancer is surgical resection combined with radiotherapy and chemotherapy $[3,4]$. Similar to other malignant tumors, distant metastasis and postoperative recurrence of colorectal cancer is a serious problem. Colorectal cancer cells not only invade the surrounding tissues and organs, but also migrate to lymph nodes and distant organs through lymph and blood circulation, resulting in incurability and death [5]. Therefore, it is of great clinical significance to study the functions of the

Abbreviations: ATAD2 - ATPase family AAA domain-containing protein 2; RNAi - RNA interference; MMPs - matrix metalloproteinases; EMT - epithelial-mesenchymal transition; ANCCA - AAA nuclear coregulator cancer-associated protein; AR - androgen receptor; ER - estrogen receptor genes that are involved in the oncogenesis, progression and metastasis of colorectal cancer.

ATPase family AAA domain-containing protein 2 (ATAD2), belonging to the ATPase family, contains an AAA (ATPase associated with various activities) domain and a bromodomain [6]. The AAA domain endows the protein with an unusually strong ATPase activity [7], and the AAA+ proteins have been demonstrated to play vital roles in various biological processes via ATPase-driven remodeling of macromolecular complexes [8]. The bromodomain is a highly conserved functional domain that specifically identifies acetylated lysine in histone or non-histone proteins. It controls the assembly of chromatin and regulates gene transcription by altering the acetylation status of histone. On the other hand, it modulates cell cycle, differentiation, signal transduction and other biological activities by modifying non-histone acetylation $[6,9]$. It has been reported that ATAD2, which is highly expressed in a variety of tumors, promotes tumor growth and metastasis, and leads to a poor prognosis in 
ovarian carcinomas [10], hepatocellular carcinoma [11] and lung adenocarcinoma [12]. ATAD2 enhances carcinogenesis of breast and prostate cancer through augmentation of estrogen receptor- and androgen receptor-mediated signaling [8, 13]. Moreover, ATAD2 coordinates with MYC by binding to the specific E-box of MYC target genes, and accelerates the progression of MYC-dependent tumors [14]. It has been reported that ATAD2 is highly expressed in colorectal cancer tissues [15], suggesting that ATAD2 may play a role in the tumorigenesis and progression of colorectal cancer. In addition, a recent study revealed that high expression of ATAD2 was correlated with advanced clinicopathological features and poor prognosis in colorectal cancer patients [16], yet the underlying mechanism remains unclear.

In this study, we established stable knockdown of ATAD2 in colorectal cancer cell lines by RNA interference, and demonstrated that ATAD2 silencing inhibited the migration and invasion of colorectal cancer cells. Moreover, ATAD2 silencing led to downregulation of matrix metalloproteinases (MMPs) and suppression of epithelial-mesenchymal transition (EMT). Our findings may provide new perspectives on the tumorigenesis, progression and treatment of colorectal cancer.

\section{Materials and methods}

Plasmid construction. In order to silence the expression of ATAD2, we designed a short hairpin RNA (shRNA) targeting 5'-GGCGATGGGTCATCAGTTA-3' of ATAD2 open read- ing frame (ORF), and synthesized complementary strands of the shRNA. After annealing, the sequence was inserted into pRNA-H1.1 vector (BamHI+HindIII). An irrelevant scramble sequence was synthesized and inserted into pRNA-H1.1 as a negative control (NC). After being verified by sequencing, the knockdown plasmid pRNA-ATAD2 shRNA and control pRNA-NC were constructed. The sequences of ATAD2 shRNA and NC are shown in Table 1.

Cell culture, transfection and establishment of stable knockdown cell lines. Colorectal cancer cell lines Caco-2 and SW-480 were purchased from Shanghai Cell Bank of Chinese Academy of Sciences. The cells were cultured in DMEM (Gibco BRL, Gaithersburg, MD, USA) supplemented with $10 \%$ fetal bovine serum (FBS) (Hyclone, Logan, UT, USA), $100 \mathrm{U} / \mathrm{ml}$ penicillin, $100 \mu \mathrm{g} / \mathrm{ml}$ streptomycin (Beyotime, Haimen, Jiangsu, China), and maintained at $37^{\circ} \mathrm{C}$ in a humidified environment of $5 \% \mathrm{CO}_{2}$. Caco-2 and SW-480 cells were seeded in 6-well plates at a density of $3 \times 10^{5} /$ well, and transfected with pRNA-NC or pRNA-ATAD2 shRNA plasmid using Lipofectamine 2000 reagent (Invitrogen, Carlsbad, CA, USA). $24 \mathrm{~h}$ later, G418 (100 $\mu \mathrm{g} / \mathrm{ml}$ ) (Invitrogen) was added into the medium to screen stably transfected cells. The G418+ medium was refreshed every two days, until stable cell clones were obtained.

RNA extraction, reverse transcription and real-time PCR. Total RNA was extracted using total RNA rapid extraction kit (BioTeke, Beijing, China) according to the manufacturer's protocol. After measuring the concentration, the

Table 1. Sequences of shRNAs and real-time PCR primers.

\begin{tabular}{|c|c|}
\hline Name & Sequence $\left(5^{c}-3^{c}\right)$ \\
\hline ATAD2 shRNA Sense & 5`-GATCCCCGGCGATGGGTCATCAGTTATTCAAGAGATAACTGATGACCCATCGCCTTTTT-3`‘ \\
\hline ATAD2 shRNA Anti-sense & 5'-AGCTAAAAAGGCGATGGGTCATCAGTTATCTCTTGAATAACTGATGACCCATCGCCGGG-3‘ \\
\hline NC Sense & 5`-GATCCCCTTCTCCGAACGTGTCACGTTTCAAGAGAACGTGACACGTTCGGAGAATTTTT-3` \\
\hline NC Anti-sense & 5'AGCTAAAAATTCTCCGAACGTGTCACGTTCTCTTGAAACGTGACACGTTCGGAGAAGGG-3` \\
\hline ATAD2 Forward & 5‘-TGGGAAATAGTTGGACCGACAC-3` \\
\hline ATAD2 Reverse & 5'-TTCTGGCAAAGCGGAATGG-3‘ \\
\hline MMP2 Forward & 5'TGCTGAAGGACACACTAAAG-3‘ \\
\hline MMP2 Reverse & 5'-GTAGCCAATGATCCTGTATGT-3‘ \\
\hline MMP9 Forward & 5'-CCAAAACTACTCGGAAGACTTGC-3‘ \\
\hline MMP9 Reverse & $5^{\prime}$-GCGACACCAAACTGGATGA-3‘ \\
\hline MMP13 Forward & 5'-CCTGGACAAGTAGTTCCAAAGG-3` \\
\hline MMP13 Reverse & 5'-AGGGATAAGGAAGGGTCACAT-3` \\
\hline E-cadherin Forward & $5^{c}$-GCCCTACCAGCCCAAAGTG-3‘ \\
\hline E-cadherin Reverse & 5'-CCGGTCAAACTGCCCATACT-3‘ \\
\hline Vimentin Forward & 5'-GACAGGCTTTAGCGAGTTATT-3' \\
\hline Vimentin Reverse & 5'-ACCGTTAGACCAGATTGATTC-3‘ \\
\hline Slug Forward & 5'GTTGCCATTGTTGAACTAAAGCC-3` \\
\hline Slug Reverse & 5'-СТССТСССССAAGGCACATACT-3‘ \\
\hline Snail Forward & 5'-GCCCCACAGGACTTTGATGA-3‘ \\
\hline Snail Reverse & 5'-AGTGAGTCTGTCAGCCTTTGTC-3‘ \\
\hline$\beta$-actin Forward & 5'-CTTAGTTGCGTTACACCCTTTCTTG-3‘ \\
\hline$\beta$-actin Reverse & 5'-CTGTCACCTTCACCGTTCCAGTTT-3‘ \\
\hline
\end{tabular}

ATAD2: ATPase family AAA domain-containing protein 2; NC: negative control; MMP: matrix metalloproteinase 
RNA was reversely transcribed into cDNA by M-MLV reverse transcriptase (BioTeke) with oligo(dT) and random primers. All reagents and instruments were pre-treated with RNase Erasol (TIANDZ, Beijing, China).

The cDNA was subjected to real-time PCR using $2 \times$ power Taq PCR MasterMix (BioTeke) and SYBR Green (Solarbio, Beijing, China) for quantitative analysis of ATAD2, E-cadherin, Vinmentin, Slug, Snail, MMP2, MMP9 and MMP13 with $\beta$-actin as the internal control. The PCR procedure was set as follows: $95^{\circ} \mathrm{C}$ for $10 \mathrm{~min}$, followed by 40 cycles of $95^{\circ} \mathrm{C}$ for $10 \mathrm{sec}, 60^{\circ} \mathrm{C}$ for $20 \mathrm{sec}$ and $72^{\circ} \mathrm{C}$ for $30 \mathrm{sec}$, and finally $4^{\circ} \mathrm{C}$ for $5 \mathrm{~min}$. The data were calculated using the $2^{-\Delta \Delta \mathrm{Ct}}$ method. The sequences of all primers used here are shown in Table 1.

Western blot. Cells were lysed with RIPA lysis buffer (Beyotime), and the proteins were separated by SDS-PAGE and transferred to polyvinylidene difluoride (PVDF) membranes (Millipore, Boston, MA, USA). After blocking with 5\% skim milk (YILI, Hohhot, Inner Mongolia, China), the PVDF membranes were incubated at $4{ }^{\circ} \mathrm{C}$ overnight with one of the following antibodies: rabbit anti-ATAD2 (1:1000) (Abcam, Cambridge, UK), mouse anti-E-cadherin (1:400) (BOSTER,

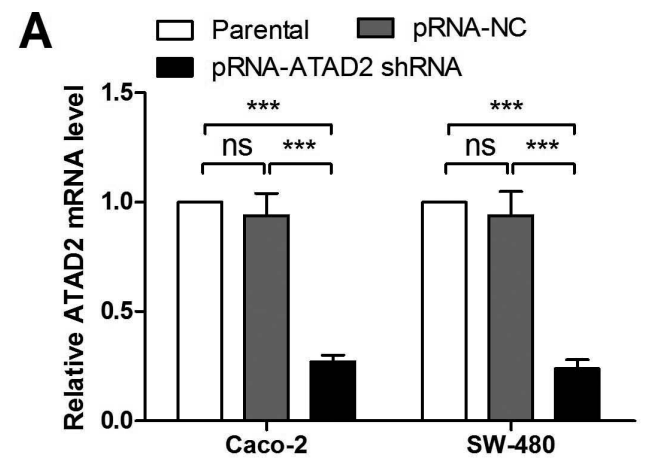

B

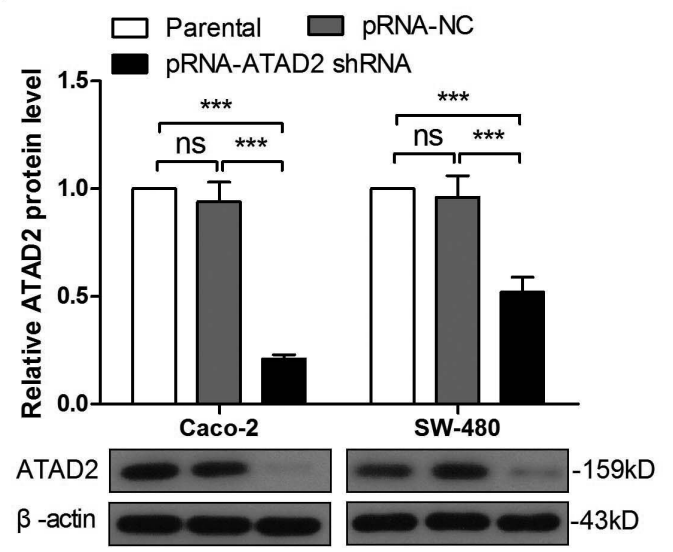

Figure 1. Establishment of ATPase family AAA domain-containing protein 2 (ATAD2) silencing cell lines.

(A, B) Real-time PCR and western blot analysis were performed to confirm the knockdown efficiency of ATAD2 shRNA in Caco-2 cells and SW-480 cells. $\left({ }^{* * *} P<0.001\right.$, ns: no significance $)$
Wuhan, Hubei, China), rabbit anti-Vimentin (1:500) (Bioss, Beijing, China), rabbit anti-Slug (1:500) (Bioss), rabbit anti-Snail (1:500) (Bioss), rabbit anti-MMP2 (1:400) (BOSTER), mouse anti-MMP9 (1:400) (BOSTER), and rabbit anti-MMP13 (1:400) (BOSTER). After rinsing with TBST, the membranes were incubated with the corresponding secondary antibodies (goat anti-rabbit or goat anti-mouse IgG-HRP) (1:5000) (Beyotime) at $37^{\circ} \mathrm{C}$ for $45 \mathrm{~min}$, followed by exposure with the ECL reagent (7sea, Shanghai, China). Thereafter, all antibodies were removed from the membranes by the stripping buffer (Beyotime), and the membranes were incubated with rabbit anti- $\beta$-actin (1:1000) (Santa Cruz, CA, USA) and goat anti-rabbit IgG-HRP (1:5000) (Beyotime) to detect the internal control, $\beta$-actin.

In vitro scratch assay. In vitro scratch assay was performed to test the migration potential of ATAD2-silenced cells. Cells were pre-treated with mitomycin C $(1 \mu \mathrm{g} / \mathrm{ml})$ (Sigma, St. Louis, MO, USA) for $1 \mathrm{~h}$ in serum-free medium. Scratch wounds were generated with a $200 \mu \mathrm{l}$ pipette tip. The gap distance of each scratch wound was photographed and measured at $0 \mathrm{~h}, 24 \mathrm{~h}$ and $48 \mathrm{~h}$ after scratching. The cells were cultured in serum-free medium during the entire course of the scratch assay.

In vitro invasion assay. In vitro invasion assay was performed with Matrigel-coated transwell chambers comprising of a polycarbonate membrane with a pore size of $8 \mu \mathrm{M}$ (Corning, NY, USA). Prior to the assay, $40 \mu \mathrm{l}$ of $2.5 \mathrm{mg} / \mathrm{ml}$ Matrigel (BD, Franklin Lakes, NJ, USA) was added onto the membrane of a transwell upper chamber which sat in a well of a 24-well plate, and the Matrigel was allowed solidify at $37^{\circ} \mathrm{C}$. Cells were trypsinized, counted and resuspended in serum-free medium. A total of $200 \mu$ cell suspension $\left(2 \times 10^{5}\right.$ cells $)$ were added into the upper chamber and $800 \mu \mathrm{l}$ DMEM with $20 \%$ FBS was added into the lower well. After $24 \mathrm{~h}$ culture, the cells on the membrane were fixed in $4 \%$ paraformaldehyde (Sinopharm, Beijing, China) for $20 \mathrm{~min}$ and stained with $0.5 \%$ crystal violet (Amresco, Solon, OH, USA) for $5 \mathrm{~min}$. The cells on the upper surface of the membrane were wiped off, and the cells on the lower surface were counted under an inverted phase contrast microscope (Motic, Xiamen, Fujian, China).

Gelatin zymography. Gelatin zymography was performed to detect the enzymatic activity of MMPs. Culture supernatant was collected and subjected to $10 \%$ SDS-PAGE containing $1 \mathrm{mg} / \mathrm{ml}$ gelatin (Sigma). Subsequently, the gel was rinsed in the eluant buffer for 40 min twice and in washing buffer for 20 min twice at room temperature to remove SDS, and incubated in the developing buffer at $37^{\circ} \mathrm{C}$ for $40 \mathrm{~h}$. After staining with Coomassie Blue for $3 \mathrm{~h}$ at room temperature, the gel was destained with destaining buffer A (30\% methyl alcohol, 10\% acetic acid) for $0.5 \mathrm{~h}, \mathrm{~B}$ (20\% methyl alcohol, 10 acetic acid) for $1 \mathrm{~h}$ and $\mathrm{C}$ (10\% methyl alcohol, $5 \%$ acetic acid) for $2 \mathrm{~h}$ at room temperature. Finally, the optical density of the band was analyzed by imaging and analyzing system (WD-9413B, LIUYI, Beijing, China).

Immunofluorescence assay. Cells were seeded on glass slides in advance. When the confluence reached $80-90 \%$, the 
cells were fixed in 4\% paraformaldehyde (Sinopharm) for 15 min, and penetrated with $0.1 \%$ TritonX-100 (Amresco) for 30 min. After blocking with $10 \%$ goat serum (Solarbio), the cells were incubated with a rabbit primary antibody against E-cadherin (1:200) (BOSTER) or Vimentin (1:200) (Bioss) at $4^{\circ} \mathrm{C}$ overnight. Subsequently, the cells were incubated with a Cy3-conjugated secondary antibody (1:200) (Beyotime) for $1 \mathrm{~h}$ in the dark at room temperature. After counter-stained with DAPI, the cells were mounted in the presence of anti fluorescence quenching agent (Solarbio), and photographed by a fluorescence microscope (Olympus, Tokyo, Japan).
Statistical analysis. The data were presented as mean \pm SD of three independent experiments. The differences among the groups were analyzed by one-way ANOVA test. It was considered statistically significant when $\mathrm{P}<0.05$. $\left({ }^{*} P<0.05,{ }^{*} P<0.01\right.$, ${ }^{* * *} P<0.001$, ns: no significance)

\section{Results}

Establishment of ATAD2 silencing cell lines. To investigate the functions of ATAD2 in colorectal cancer, we constructed an ATAD2 knockdown plasmid pRNA-ATAD2
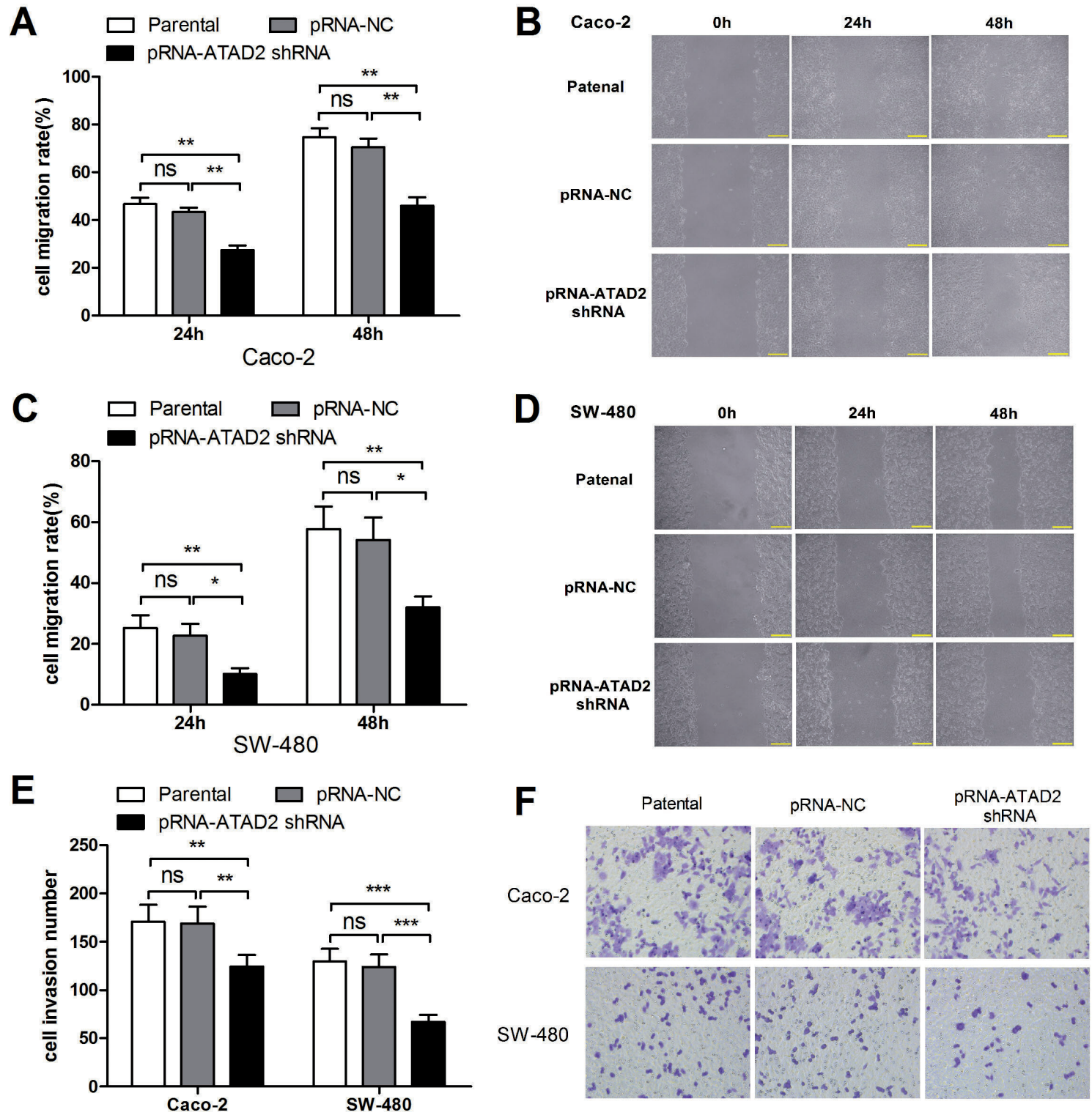

Figure 2. Silencing of ATAD2 inhibits migration and invasion of colorectal cancer cells.

(A-D) Scratch assay was performed to assess the migration potential in Caco-2 and SW-480 cells. (B, D) The representative horizons of the scratch wounds in Caco-2 and SW-480 monolayers. The scale bars represent $100 \mu \mathrm{m}$. (E, F) Transwell assay was performed to detect effect of ATAD2 silencing on the invasion of Caco- 2 cells and SW-480 cells. $\left({ }^{\star} P<0.05,{ }^{*} P<0.01,{ }^{* * *} P<0.001\right.$, ns: no significance) 
shRNA and a control plasmid pRNA-NC. The plasmids were transfected into Caco-2 and SW- 480 cells. By screening with G418, we obtained 4 stably transfected cell lines: Caco-2/ pRNA-NC, Caco-2/pRNA-ATAD2 shRNA, SW-480/pRNANC and SW-480/pRNA-ATAD2 shRNA. Next, the silencing efficiency of pRNA-ATAD2 shRNA was determined by real-time PCR and western blot. Compared to the pRNANC-transfected cells, pRNA-ATAD2 shRNA led to reduction of ATAD2 mRNA by $71 \%$ in Caco- 2 cells and by $74 \%$ in SW-480 cells (Figure 1A), as well as reduction of ATAD2 protein by $78 \%$ in Caco-2 cells and by $46 \%$ in SW-480 cells (Figure 1B). The silencing efficiency of ATAD2 silencing was sufficient in both Caco-2 cells and SW-480 cells for the subsequent experiments.

Silencing of ATAD2 inhibits migration and invasion of colorectal cancer cells in vitro. To explore the role of ATAD2 in the migration and invasion of colorectal cancer cells, in vitro scratch assay and transwell assay were carried out. Scratch assay results showed that silencing of ATAD2 decreased the rate of migrating Caco- 2 cells by $37 \%$ and $35 \%$ in $24 \mathrm{~h}$ and $48 \mathrm{~h}$, respectively (Figure 2A, 2B), and also decreased the migration rate by $56 \%$ and $41 \%$ in $24 \mathrm{~h}$ and $48 \mathrm{~h}$, respectively, in SW- 480 cells (Figure 2C, 2D). Transwell assay indicated that silencing of ATAD2 reduced the number of invading Caco- 2 cells and SW- 480 cells by $27 \%$ and $46 \%$, respectively, as compared with NC (Figure 2E, 2F). These results demonstrated that silenc- ing of ATAD2 inhibited migration and invasion of colorectal cancer cells in vitro.

Silencing of ATAD2 suppresses EMT in colorectal cancer cells. Since enhanced tumor cell migration and invasion is frequently associated with EMT, we next explored if ATAD2 was involved in the EMT process in colorectal cancer cells. Currently, EMT is usually assessed by a group of epithelial and mesenchymal markers, the expression levels of which are markedly altered during EMT. Here, we tested the expression of an epithelial marker E-cadherin, and a number of mesenchymal markers including Vimentin, Slug and Snail.

Real-time PCR results indicated that silencing of ATAD2 increased the level of E-cadherin mRNA level by 2.77 folds (Figure $3 \mathrm{~A}$ ), and decreased the mRNA of Vimentin by $50 \%$ (Figure 3B), Slug by $46 \%$ (Figure 3C) and Snail by $41 \%$ (Figure 3D) in Caco-2 cells. At the same time, western blot results showed that silencing of ATAD2 increased the level of E-cadherin protein by 2.54 folds (Figure $4 \mathrm{~A}$ ), and decreased protein level of Vimentin by $45 \%$ (Figure 4B), Slug by $37 \%$ (Figure $4 \mathrm{C}$ ) and Snail by $59 \%$ in Caco- 2 cells (Figure 4D). Similar results were obtained in SW-480 cells (Figure 3 , Figure 4). Moreover, immunofluorescence assay further demonstrated that silencing of ATAD2 upregulated the expression of E-cadherin and downregulated the expression of Vimentin in Caco-2 and SW-480 cells (Figure 5A-D). These
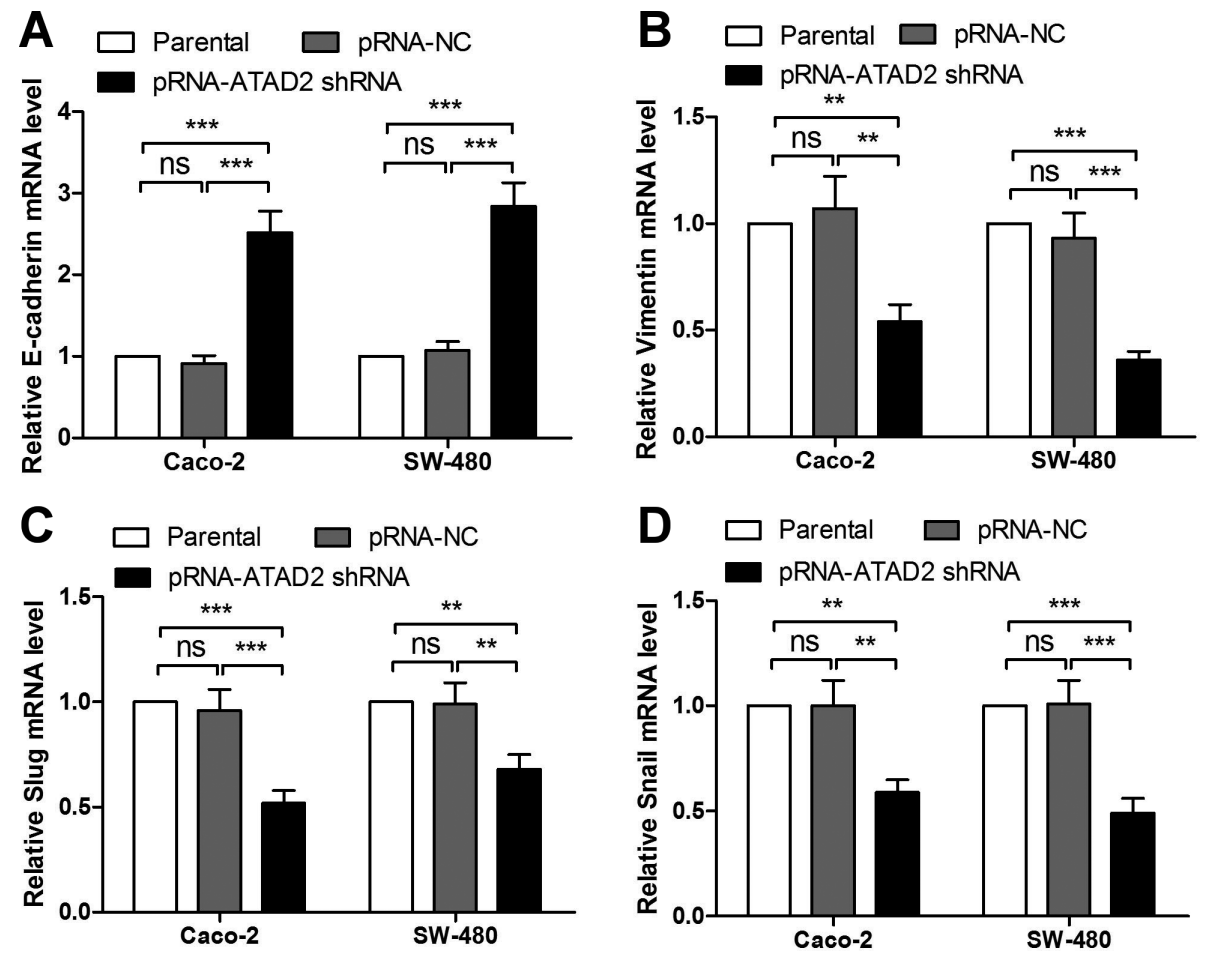

Figure 3. ATAD2 regulates transcription of molecular markers of epithelial-mesenchymal transition (EMT).

(A-D) Real-time PCR was performed to detect the mRNA levels of E-cadherin, Vimentin, Slug and Snail in Caco-2 cells and SW-480 cells with or without ATAD2 silencing. $\left({ }^{* *} P<0.01,{ }^{* *} P<0.001\right.$, ns: no significance $)$ 
results suggested that silencing of ATAD2 suppressed EMT in colorectal cancer cells.

Silencing of ATAD2 reduces expression and enzymatic activity of MMPs in colorectal cancer cells. MMPs are required during cell invasion to dismantle the extracellular matrix for penetration through the endothelium [17]. Since the previous results had shown the impact of ATAD2 on the invasion of colorectal cancer cells, we next detected if ATAD2 affected the expression and/or the enzymatic activity of MMPs.

Real-time PCR and western blot results revealed that, when ATAD2 was silenced in Caco-2 cells, the mRNA levels of MMP2, MMP9 and MMP13 decreased by $33 \%, 54 \%$ and $57 \%$, respectively (Figure 6A, 6C, 6E), and their protein levels decreased by $63 \%, 61 \%$ and $57 \%$, respectively (Figure 6B, 6D, 6F). Consistent declines in the mRNA and protein levels of MMPs were observed in SW-480 cells (Figure 6A-F). In addition, gelatin zymography was performed to evaluate the enzymatic activity of MMP9 and MMP2. As shown in Figure 7, the enzymatic activity of MMP9 decreased by $48 \%$ in Caco- 2 cells and by $71 \%$ in SW-480 cells as a results of ATAD2 silencing.
Similarly, ATAD2 silencing decreased the enzymatic activity of MMP2 by $64 \%$ and $73 \%$ in Caco- 2 and SW- 480 cells, respectively (Figure7A, 7B). Thus we concluded that silencing of ATAD2 downregulated the expression of MMPs and reduced their enzymatic activity in colorectal cancer cells.

\section{Discussion}

ATAD2, also known as AAA nuclear coregulator cancerassociated protein (ANCCA), has been previously reported as an oncogene that is related to the tumorigenesis, progression and poor prognosis of a variety of tumors like breast cancer, hepatocellular carcinoma and osteosarcoma [18-20]. In this study, we established ATAD2 knockdown cell lines by RNA interference, and found that silencing of ATAD2 expression inhibited migration and invasion, suppressed EMT, and decreased MMPs expression and activity in Caco- 2 and SW-480 cells.

The potential of migration and invasion is associated with the malignant degree of tumor cells, and it is a crucial reason for incurability and high mortality of malignant tumors, including colorectal cancer, as compared with benign tumors.
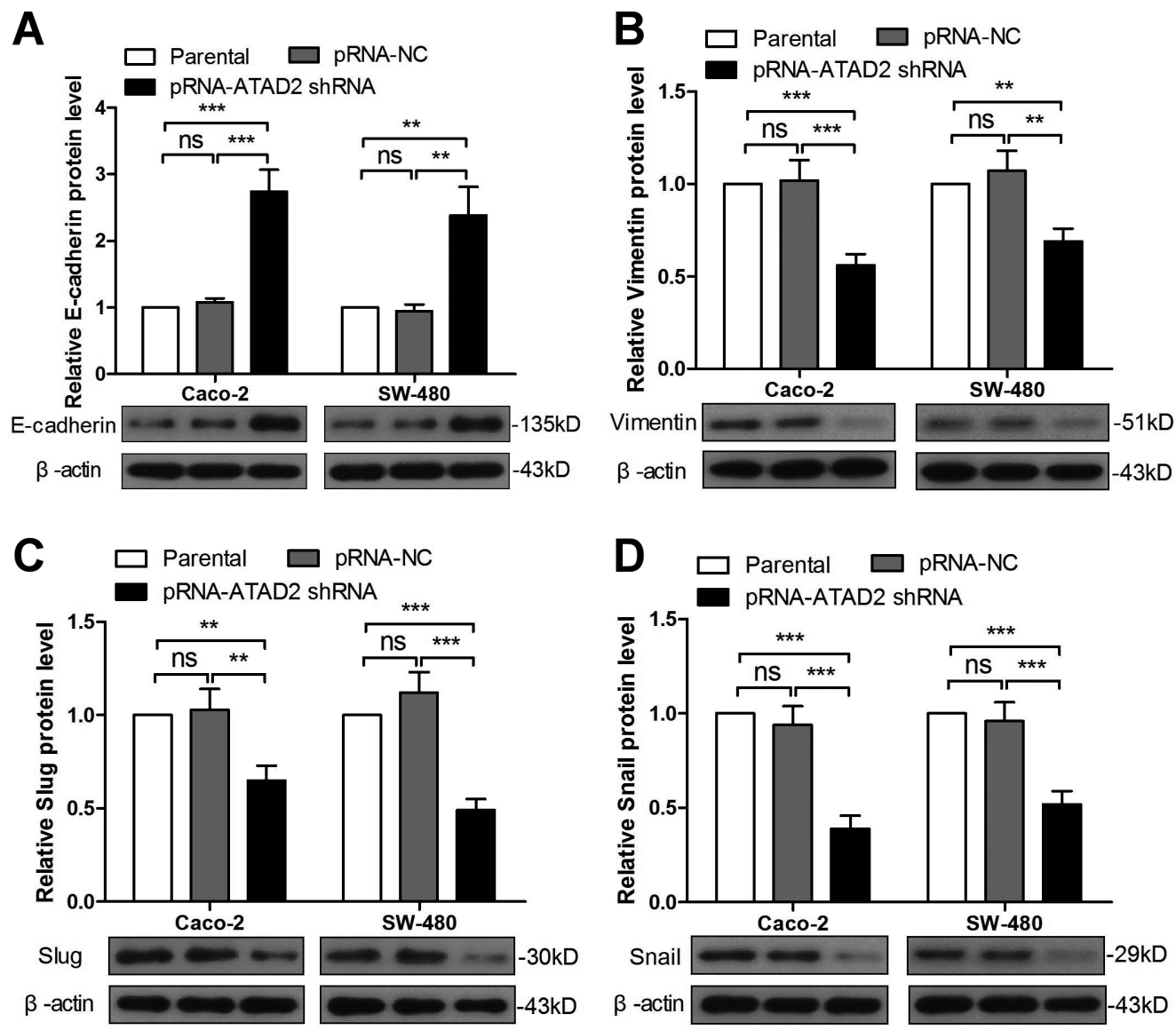

Figure 4. Silencing of ATAD2 alters the expression of EMT markers.

(A-D) Western blot was performed to measure the protein expression of E-cadherin, Vimentin, Slug and Snail in ATAD2-silenced Caco-2 and SW-480 cells. $\left({ }^{*} P<0.01,{ }^{* * * P}<0.001\right.$, ns: no significance) 
Tumor cells in the primary lesion invade vascular endothelium or lymphatic vessels, travel to distant organs or tissues via peripheral circulation, and propagate there to form metastatic tumors. Malignant tumor cells of a higher degree usually have a stronger potential in migration and invasion. In our study, the in vitro scratch assay and transwell assay demonstrated that silencing of ATAD2 weakened the capacity of migration and invasion in Caco-2 and SW-480 cells, which is consist with the findings in hepatocellular carcinoma [11] and cervical cancer [21].

The migration and invasion of epithelial tumor cells are usually achieved by EMT. During EMT, E-cadherin is replaced by $\mathrm{N}$-cadherin, and keratin cytoskeleton is replaced by Vimentin cytoskeleton. In the meanwhile, cells lose polarity, and the adhesion junctions of cell-cell and cell-basement membrane are disrupted, thus the transformed tumor cells are prone to move [22]. Several transcription factors, such as Snail, Slug, Zeb-1 and Twist, are upregulated during EMT [23]. Moreover, MMPs are secreted to dissolve the extracellular matrix, facilitating the tumor cells to penetrate through the endothelium [24-26]. Via migration and invasion, one primary tumor could spread to several organs and form multiple metastases. Colorectal cancer, for example, may form liver metastasis [27], lung metastasis [28], bone metastasis [29] and lymph node metastasis [30]. It has been reported that ATAD2 is highly expressed in colorectal cancer, and it is associated with liver metastasis, lymph node metastasis and poor prognosis of colorectal cancer patients [16]. In our study, we detected the expression of epithelial and mesenchymal markers (E-cadherin, Vimentin, Slug and Snail) in Caco- 2 and SW-480 cells, and found that E-cadherin was increased, whereas Vimentin, Slug and Snail were decreased after knockdown of ATAD2, which represented a suppressed EMT. In addition, we examined the expression and activity of
A

\section{Caco-2}
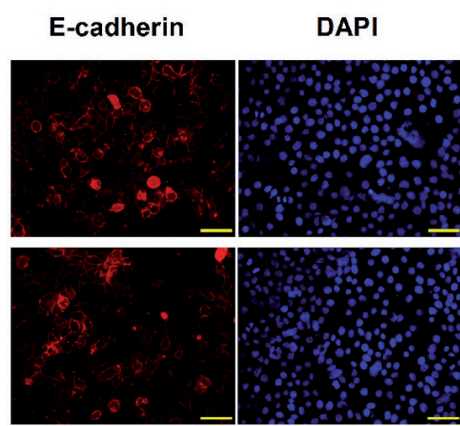

Patental

$$
\text { PRNA-NC }
$$

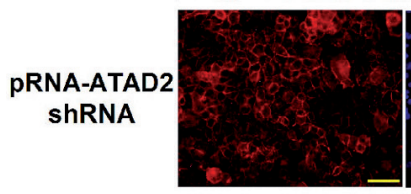

C

Caco-2

Parental
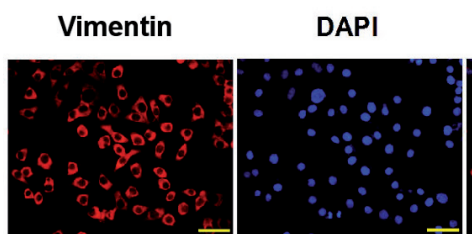

pRNA-NC
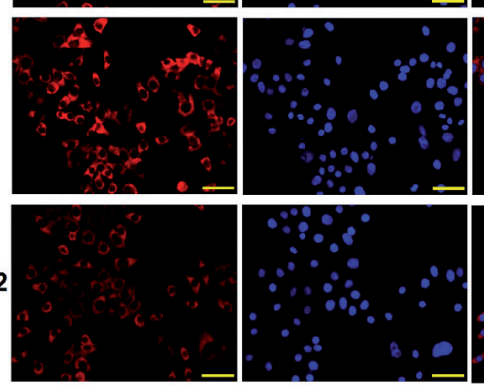
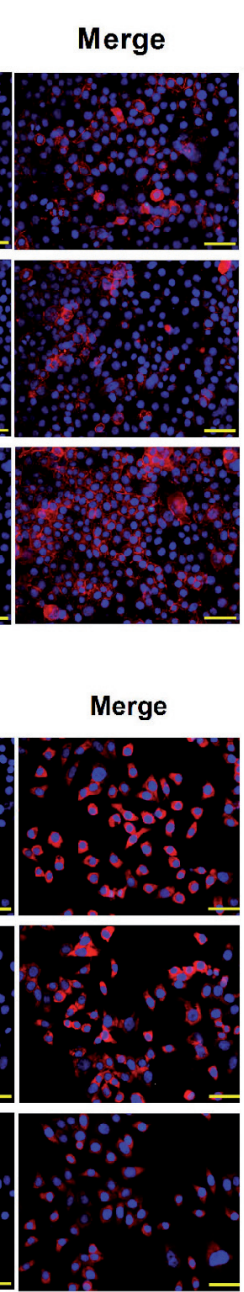

B

SW -480
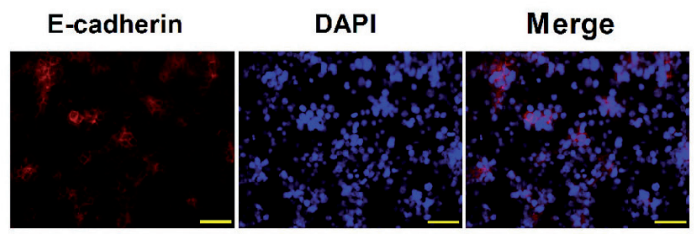

pRNA-NC
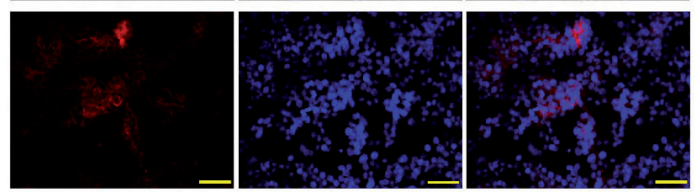

pRNA-ATAD2 shRNA
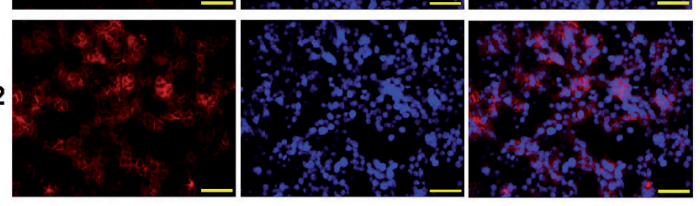

\section{D}
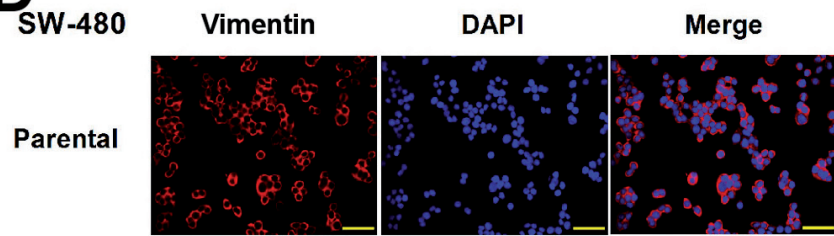

pRNA-NC
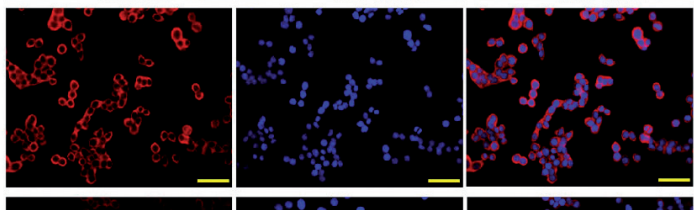

PRNA-ATAD2 shRNA
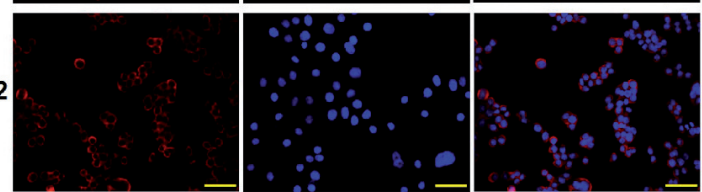

Figure 5. Immunofluorescence assay of EMT markers.

(A, B) E-cadherin and (C, D) Vimentin were examined by immunofluorescence assay to examine the EMT progress in ATAD2-silenced Caco-2 and SW-480 cells. The scale bars represent $50 \mu \mathrm{m}$. 

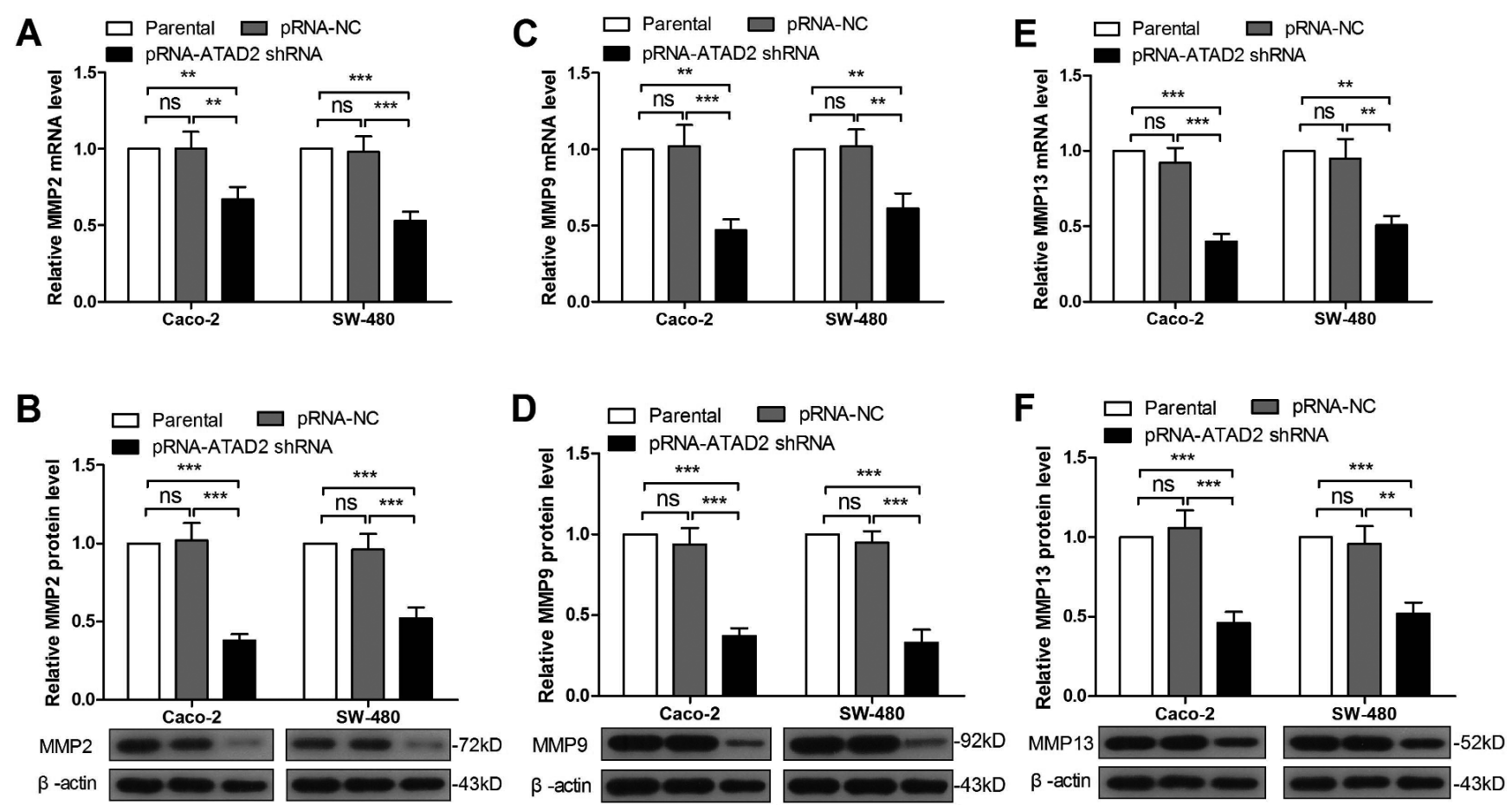

Figure 6. Silencing of ATAD2 downregulates the expression of matrix metalloproteinase (MMPs).

(A, C, E) Real-time PCR was performed to detect the mRNA levels of MMP2, MMP9 and MMP13 in Caco-2 cells and SW-480 cells with or without ATAD2 knockdown. (B, D, F) Western blot was used to determine the protein levels of MMP2, MMP9 and MMP13 in Caco-2 and SW-480 cells with or without ATAD2 silencing. $\left({ }^{* * P}<0.01,{ }^{* *} P<0.001\right.$, ns: no significance)
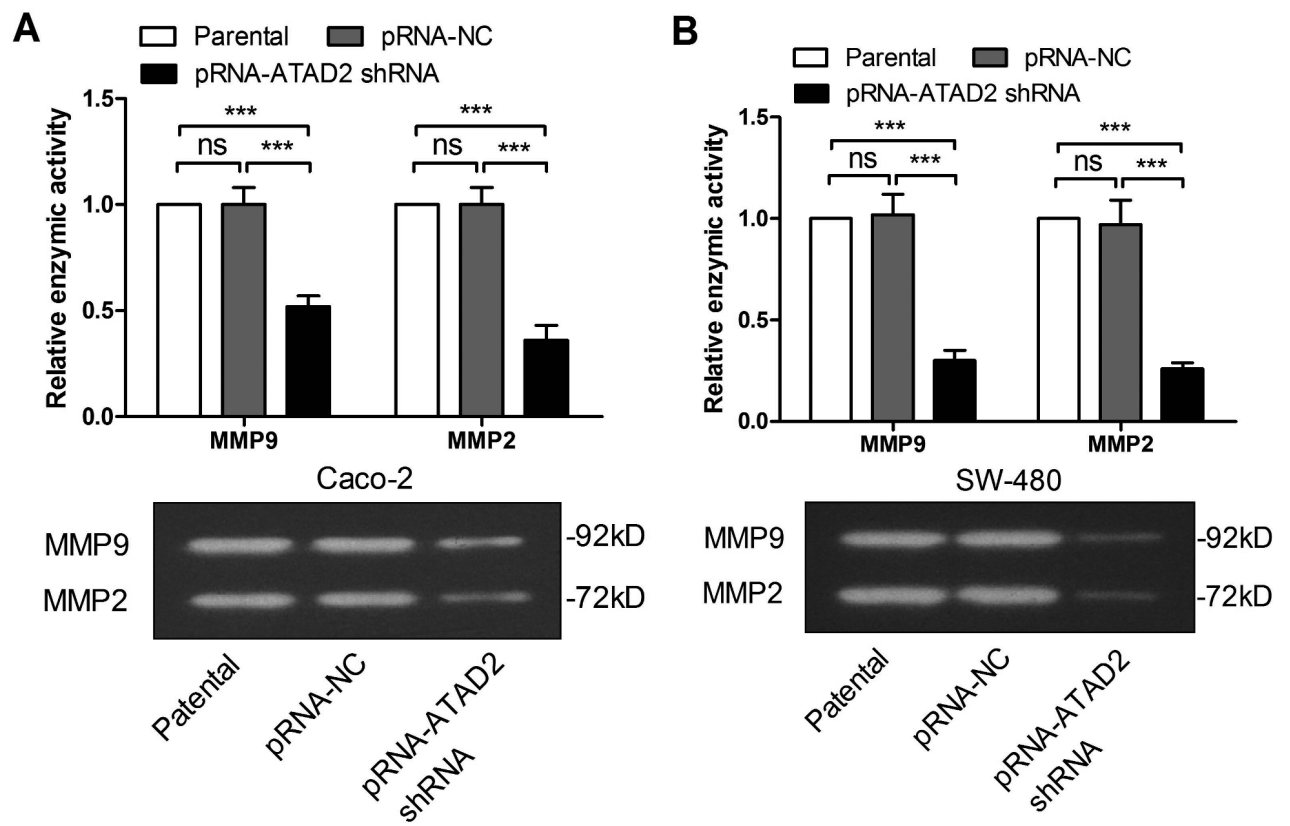

Figure 7. Silencing of ATAD2 reduces enzymatic activity of MMPs.

(A, B) Gelatin zymography was performed to detect the enzymatic activity of MMP2 and MMP9 in Caco-2 and SW-480 cells after ATAD2silencing. $\left({ }^{* * *}<<0.001\right.$, ns: no significance) 
MMPs, and showed that ATAD2 silencing led to depressed expression and enzymatic activity of MMPs. This may explain how ATAD2 regulates colorectal cancer metastasis.

Previous studies have reported different molecular mechanisms through which ATAD2 influences the development of various tumors. For example, ATAD2 directly interacts with E2Fs, and activates the transcription of key cell cycle genes resulted in accelerated proliferation of breast cancer cells [31]. In prostate cancer, ATAD2 interacts with androgen receptor (AR), and augments transcriptional activation of androgen-stimulated genes, which favors cancer cells survival and proliferation [13]. ATAD2 is also required for estrogen receptor (ER) a-activated transcription of target genes in breast cancer cells [8]. In this study, we report for the first time that ATAD2 promotes metastasis of colorectal cancer cells by regulating EMT, migration and MMPs-mediated invasion.

All the detected EMT markers in this study were changed in both mRNA and protein levels in response to ATAD2 silencing, suggesting that ATAD2 may function at the transcriptional level. Comprising of an AAA domain and a bromodomain, ATAD2 is enabled to identify histone acetylation and participate in chromosomal remodeling and gene transcription $[6,32]$. ATAD2 is adjacent to MYC, and they are both mapped to chromosome 8q24, a most commonly amplified region in many types of cancer [33]. MYC is a well-known oncogene, which is often activated and amplified by chromosomal translocation [34-36]. ATAD2, in close proximity to $M Y C$, is essential to MYC-dependent tumors by binding to the E-box of MYC target genes [37]. Therefore, the pro-metastatic function of ATAD2 is likely to be related to MYC and its target genes, yet the detail molecular mechanism needs to be elucidated in further studies.

In conclusion, we demonstrated that silencing of ATAD2 inhibited migration and invasion of colorectal cancer cells by suppressing EMT, downregulating MMPs expression and weakening their activity, which may illuminate the prometastatic function of ATAD2 in colorectal cancer. We report, for the first time, the mechanism underlying the positive role of ATAD2 in the migration and invasion of colorectal cancer cells, and our study may provide new insights into the tumorigenesis and metastasis of colorectal cancer.

\section{References}

[1] BRENNER H, KLOOR M, POX CP. Colorectal cancer. Lancet 2014; 383: 1490-1502. http://dx.doi.org/10.1016/S0140-6736(13)61649-9

[2] CASTELLS A. Choosing the optimal method in programmatic colorectal cancer screening: current evidence and controversies. Therap Adv Gastroenterol 2015; 8: 221-233. http://dx.doi.org/10.1177/1756283X15578610

[3] BUJKO K, GLIMELIUS B, VALENTINI V, MICHALSKI W, SPALEK M. Postoperative chemotherapy in patients with rectal cancer receiving preoperative radio(chemo)therapy: A meta-analysis of randomized trials comparing surgery
+/- a fluoropyrimidine and surgery + a fluoropyrimidine + /oxaliplatin. Eur J Surg Oncol 2015; 41: 713-723. http://dx.doi. org/10.1016/j.ejso.2015.03.233

[4] KIM JH. Chemotherapy for colorectal cancer in the elderly. World journal of gastroenterology : World J Gastroenterol 2015; 21: 5158-5166. http://dx.doi.org/10.3748/wjg.v21. i17.5158

[5] WORNI M, SHAH KN, CLARY BM. Colorectal cancer with potentially resectable hepatic metastases: optimizing treatment. Curr Oncol Rep 2014; 16: 407. http://dx.doi. org/10.1007/s11912-014-0407-z

[6] BOUSSOUAR F, JAMSHIDIKIA M, MOROZUMI Y, ROUSSEAUX S, KHOCHBIN S. Malignant genome reprogramming by ATAD2. Biochim Biophys Acta 2013; 1829: 1010-1014. http://dx.doi.org/10.1016/j.bbagrm.2013.06.003

[7] PENG W, LIN Z, LI W, LU J, SHEN Y et al. Structural insights into the unusually strong ATPase activity of the AAA domain of the Caenorhabditis elegans fidgetin-like 1 (FIGL-1) protein. J Biol Chem 2013; 288: 29305-29312. http://dx.doi. org/10.1074/jbc.M113.502559

[8] ZOU JX, REVENKO AS, LI LB, GEMO AT, CHEN $\mathrm{HW}$. ANCCA, an estrogen-regulated AAA+ ATPase coactivator for ERalpha, is required for coregulator occupancy and chromatin modification. Proc Natl Acad Sci U S A 2007; 104: 18067-18072. http://dx.doi.org/10.1073/ pnas.0705814104

[9] SANCHEZ R, MESLAMANI J, ZHOU MM. The bromodomain: from epigenome reader to druggable target. Biochim Biophys Acta 2014; 1839: 676-685. http://dx.doi. org/10.1016/j.bbagrm.2014.03.011

[10] WAN WN, ZHANG YX, WANG XM, LIU YJ, ZHANG YQ et al. ATAD2 is highly expressed in ovarian carcinomas and indicates poor prognosis. Asian Pac J Cancer Prev 2014; 15: 2777-2783. http://dx.doi.org/10.7314/ APJCP.2014.15.6.2777

[11] WU G, LIU H, HE H, WANG Y, LU X et al. miR-372 downregulates the oncogene ATAD2 to influence hepatocellular carcinoma proliferation and metastasis. BMC Cancer 2014; 14: 107. http://dx.doi.org/10.1186/1471-2407-14-107

[12] FOURET R, LAFFAIRE J, HOFMAN P, BEAU-FALLER $\mathrm{M}$, MAZIERES J et al. A comparative and integrative approach identifies ATPase family, AAA domain containing 2 as a likely driver of cell proliferation in lung adenocarcinoma. Clin Cancer Res 2012; 18: 5606-5616. http://dx.doi. org/10.1158/1078-0432.CCR-12-0505

[13] ZOU JX, GUO L, REVENKO AS, TEPPER CG, GEMO AT et al. Androgen-induced coactivator ANCCA mediates specific androgen receptor signaling in prostate cancer. Cancer Res 2009; 69: 3339-3346. http://dx.doi.org/10.1158/0008-5472. CAN-08-3440

[14] CIRO M, PROSPERINI E, QUARTO M, GRAZINI U, WALFRIDSSON J et al. ATAD2 is a novel cofactor for MYC, overexpressed and amplified in aggressive tumors. Cancer Res 2009; 69: 8491-8498. http://dx.doi.org/10.1158/0008-5472. CAN-09-2131

[15] RAMASWAMY S, TAMAYO P, RIFKIN R, MUKHERJEE $\mathrm{S}$, YEANG $\mathrm{CH}$ et al. Multiclass cancer diagnosis using 
tumor gene expression signatures. Proc Natl Acad Sci U S A 2001; 98: 15149-15154. http://dx.doi.org/10.1073/ pnas. 211566398

[16] LUO Y, YE GY, QIN SL, YU MH, MU YF et al. ATAD2 Overexpression Identifies Colorectal Cancer Patients with Poor Prognosis and Drives Proliferation of Cancer Cells. Gastroenterol Res Pract 2015; 2015: 936564. http://dx.doi. org/10.1155/2015/936564

[17] ZEISBERG M, MAESHIMA Y, MOSTERMAN B, KALLURI R. Renal fibrosis. Extracellular matrix microenvironment regulates migratory behavior of activated tubular epithelial cells. Am J Pathol 2002; 160: 2001-2008. http://dx.doi. org/10.1016/S0002-9440(10)61150-9

[18] KALASHNIKOVA EV, REVENKO AS, GEMO AT, ANDREWS NP, TEPPER CG et al. ANCCA/ATAD2 overexpression identifies breast cancer patients with poor prognosis, acting to drive proliferation and survival of triplenegative cells through control of B-Myb and EZH2. Cancer Res 2010; 70: 9402-9412. http://dx.doi.org/10.1158/00085472.CAN-10-1199

[19] HWANG HW, HA SY, BANG H, PARK CK. ATAD2 as a Poor Prognostic Marker for Hepatocellular Carcinoma after Curative Resection. Cancer Res Treat 2015; 47: 853-861. http:// dx.doi.org/10.4143/crt.2014.177

[20] FELlENBERG J, BERND L, DELling G, WitTE D, ZAHLTEN-HINGURANAGE A. Prognostic significance of drug-regulated genes in high-grade osteosarcoma. Mod Pathol 2007; 20: 1085-1094. http://dx.doi.org/10.1038/modpathol.3800937

[21] ZHENG L, LI T, ZHANG Y, GUO Y, YAO J et al. Oncogene ATAD2 promotes cell proliferation, invasion and migration in cervical cancer. Oncol Rep 2015; 33: 2337-2344.

[22] KALLURI R, NEILSON EG. Epithelial-mesenchymal transition and its implications for fibrosis. J Clin Invest 2003; 112: 1776-1784. http://dx.doi.org/10.1172/JCI200320530

[23] LINDSEY S, LANGHANS SA. Crosstalk of Oncogenic Signaling Pathways during Epithelial-Mesenchymal Transition. Front Oncol 2014; 4: 358. http://dx.doi.org/10.3389/ fonc. 2014.00358

[24] LAMOUILLE S, XU J, DERYNCK R. Molecular mechanisms of epithelial-mesenchymal transition. Nat Rev Mol Cell Biol 2014; 15: 178-196. http://dx.doi.org/10.1038/nrm3758

[25] VELLA LJ. The emerging role of exosomes in epithelialmesenchymal-transition in cancer. Front Oncol 2014; 4: 361. http://dx.doi.org/10.3389/fonc.2014.00361

[26] CAO H, XU E, LIU H, WAN L, LAI M. Epithelial-mesenchymal transition in colorectal cancer metastasis: A system review. Pathol Res Pract 2015; 211: 557-569. http://dx.doi. org/10.1016/j.prp.2015.05.010
[27] LI W, CHANG J, WANG S, LIU X, PENG J et al. miRNA99b-5p suppresses liver metastasis of colorectal cancer by down-regulating mTOR. Oncotarget 2015; 6: 24448-24462. http://dx.doi.org/10.18632/oncotarget.4423

[28] OH SY, KIM DO Y, SUH KW. Oncologic outcomes following metastasectomy in colorectal cancer patients developing distant metastases after initial treatment. Ann Surg Treat Res 2015; 88: 253-259. http://dx.doi.org/10.4174/ astr.2015.88.5.253

[29] SUN C, DENG Y, ZHOU H, HU ZQ. Risk factors for the development of metachronous bone metastasis in colorectal cancer patients after curative resection. Int J Surg 2015; 21: 145-149. http://dx.doi.org/10.1016/j.ijsu.2015.07.706

[30] FANG W, FU C, CHEN X, MOU X, LIU F et al. Neurokinin-2 receptor polymorphism predicts lymph node metastasis in colorectal cancer patients. Oncol Lett 2015; 9: 2003-2006. http://dx.doi.org/10.3892/ol.2015.3016

[31] REVENKO AS, KALASHNIKOVA EV, GEMO AT, ZOU JX, CHEN HW. Chromatin loading of E2F-MLL complex by cancer-associated coregulator ANCCA via reading a specific histone mark. Mol Cell Biol 2010; 30: 5260-5272. http:// dx.doi.org/10.1128/MCB.00484-10

[32] CARON C, LESTRAT C, MARSAL S, ESCOFFIER E, CURTET $S$ et al. Functional characterization of ATAD2 as a new cancer/testis factor and a predictor of poor prognosis in breast and lung cancers. Oncogene 2010; 29: 5171-5181. http://dx.doi.org/10.1038/onc.2010.259

[33] BEROUKHIM R, MERMEL CH, PORTER D, WEI G, RAYCHAUDHURI $S$ et al. The landscape of somatic copy-number alteration across human cancers. Nature 2010; 463: 899-905. http://dx.doi.org/10.1038/nature08822

[34] TAUB R, KIRSCH I, MORTON C, LENOIR G, SWAN D et al. Translocation of the $\mathrm{c}$-myc gene into the immunoglobulin heavy chain locus in human Burkitt lymphoma and murine plasmacytoma cells. Proc Natl Acad Sci U S A 1982; 79: 7837-7841. http://dx.doi.org/10.1073/pnas.79.24.7837

[35] BOXER LM, DANG CV. Translocations involving c-myc and c-myc function. Oncogene 2001; 20: 5595-5610. http://dx.doi. org/10.1038/sj.onc. 1204595

[36] KAWATE S, FUKUSATO T, OHWADA S, WATANUKI A, MORISHITA Y. Amplification of c-myc in hepatocellular carcinoma: correlation with clinicopathologic features, proliferative activity and p53 overexpression. Oncology 1999; 57: 157-163. http://dx.doi.org/10.1159/000012024

[37] RAEDER MB, BIRKELAND E, TROVIK J, KRAKSTAD C, SHEHATA $S$ et al. Integrated genomic analysis of the $8 \mathrm{q} 24$ amplification in endometrial cancers identifies ATAD2 as essential to MYC-dependent cancers. PloS One 2013; 8: e54873. http://dx.doi.org/10.1371/journal.pone.0054873 